\title{
Cryptic diversity and deep divergence in an upper Amazonian leaflitter frog, Eleutherodactylus ockendeni Kathryn R Elmer ${ }^{1,3}$, José A Dávila² and Stephen C Lougheed*1
}

Address: ${ }^{1}$ Department of Biology, Queen's University, Kingston, ON, K7L 3N6, Canada, ${ }^{2}$ Instituto de Investigación en Recursos Cinegéticos, IREC (CSIC, UCLM, JCCM), Ronda de Toledo s/n, 13005 Ciudad Real, Spain and ${ }^{3}$ Current address : Lehrstuhl für Zoologie und Evolutionsbiologie, Department of Biology, University of Konstanz, Universitätstraße 10, 78457 Konstanz, Germany

Email: Kathryn R Elmer - kathryn.elmer@uni-konstanz.de; José A Dávila - jadavila@irec.uclm.es; Stephen C Lougheed* - steve.lougheed@queensu.ca

* Corresponding author

Published: 21 December 2007

BMC Evolutionary Biology 2007, 7:247 doi:10.1/86/147|-2/48-7-247
Received: 3 December 2006

Accepted: 13 September 2007

This article is available from: http://www.biomedcentral.com/I47I-2/48/7/247

(c) 2007 Elmer et al; licensee BioMed Central Ltd.

This is an Open Access article distributed under the terms of the Creative Commons Attribution License (http://creativecommons.org/licenses/by/2.0), which permits unrestricted use, distribution, and reproduction in any medium, provided the original work is properly cited.

\begin{abstract}
Background: The forests of the upper Amazon basin harbour some of the world's highest anuran species richness, but to date we have only the sparsest understanding of the distribution of genetic diversity within and among species in this region. To quantify region-wide genealogical patterns and to test for the presence of deep intraspecific divergences that have been documented in some other neotropical anurans, we developed a molecular phylogeny of the wide-spread terrestrial leaflitter frog Eleutherodactylus ockendeni (Leptodactylidae) from 13 localities throughout its range in Ecuador using data from two mitochondrial genes ( $16 \mathrm{~S}$ and cyt b; 1246 base pairs). We examined the relation between divergence of mtDNA and the nuclear genome, as sampled by five speciesspecific microsatellite loci, to evaluate indirectly whether lineages are reproductively isolated where they co-occur. Our extensive phylogeographic survey thus assesses the spatial distribution of $E$. ockendeni genetic diversity across eastern Ecuador.
\end{abstract}

Results: We identified three distinct and well-supported clades within the Ecuadorean range of $E$. ockendeni: an uplands clade spanning north to south, a northeastern and central lowlands clade, and a central and southeastern clade, which is basal. Clades are separated by $12 \%$ to $15 \%$ net corrected $\mathrm{p}$-distance for cytochrome $b$, with comparatively low sequence divergence within clades. Clades marginally overlap in some geographic areas (e.g., Napo River basin) but are reproductively isolated, evidenced by diagnostic differences in microsatellite PCR amplification profiles or DNA repeat number and coalescent analyses (in MDIV) best modelled without migration. Using Bayesian (BEAST) and net phylogenetic estimates, the Southeastern Clade diverged from the Upland/ Lowland clades in the mid-Miocene or late Oligocene. Lowland and Upland clades speciated more recently, in the early or late Miocene.

Conclusion: Our findings uncover previously unsuspected cryptic species diversity within the common leaflitter frog $E$. ockendeni, with at least three different species in Ecuador. While these clades are clearly geographically circumscribed, they do not coincide with any existing landscape barriers. Divergences are ancient, from the Miocene, before the most dramatic mountain building in the Ecuadorean Andes. Therefore, this diversity is not a product of Pleistocene refuges. Our research coupled with other studies suggests that species richness in the upper Amazon is drastically underestimated by current inventories based on morphospecies. 


\section{Background}

Species richness and genetic diversity within species are proposed to co-vary and understanding the details of this relationship is critical to unifying biodiversity theory [1]. Though the forests of the upper Amazon basin are a renowned hotspot for amphibian species richness [2], thus far there have been few explorations of the phylogeographic and population-level patterns in the region's amphibian taxa [3-9]. Consequently, we have only a preliminary knowledge of the distribution of genetic diversity from merely a handful of amphibian species in the megadiverse upper Amazon. With the aim of augmenting our understanding of spatial patterns of genetic diversity and details of evolutionary history in this famously species-rich area, we assessed the diversity in a widespread upper Amazonian frog species across the upper Amazon of Ecuador.

Historical and environmental characteristics of a region influence multiple levels of diversity, both in its origin and maintenance $[1,10-12]$. Numerous regional historical, topographical, and ecological factors of the Andes and Amazon have been suggested as influential in the diversification of species, for example: riverine barriers [13-16]; large uninterrupted area [10,17]; an Andean "species pump" promoted by complex, isolating montane topography and vegetation [18]; Pleistocene forest refuges [11,19-21]; complex biotic interactions [22,23]; ancient ridges and other palaeogeographic features $[4,24]$; ancientness [25]; and relative youth of the Andes [26]. For amphibians, complex topography may restrict vagility and produce marked population subdivision, and ultimately patterns of adaptive radiation or isolation patterns that are potentially implicated in high local rates of speciation [27]. There are many confounds in the upper Amazon that make exclusive testing of any one of these factors challenging because multiple causes at various historical timescales are surely involved in the origination of diversity $[8,28]$. Nonetheless, contributing temporal and geographical patterns of diversity in phylogeographic studies allows us to discern among some of the diversification hypotheses (e.g., ancientness versus youth, orogenesis events versus recent climatic change). Assessing these patterns is critical to disentangling the causes of within and among species diversification and the genesis of anuran biodiversity, especially as this region increasingly suffers deforestation.

Here we use mitochondrial and nuclear DNA to quantify the phylogeography and population structure of a terrestrial upper Amazonian leaflitter frog, Eleutherodactylus ockendeni (Leptodactylidae). We sampled from 13 localities across the species range in megadiverse eastern Ecuador to develop a thorough regional phylogeographic survey. Further, we used phylogenetic and multiple coalescent meth- ods to estimate the depth of divergence among clades and suggest temporal context for the divergence revealed by our analyses.

\section{Results \\ DNA sequences}

We sequenced 105 individuals for cytochrome $b$ (cyt $b$ ) and 45 individuals for 16S, plus two outgroup taxa (Additional file 1). Ingroup base frequencies are similar to those found in other frogs [29]: cyt $b: \mathrm{A}=0.240, \mathrm{C}=0.313, \mathrm{G}=$ $0.145, \mathrm{~T}=0.301 ; 16 \mathrm{~S}: \mathrm{A}=0.299, \mathrm{C}=0.251, \mathrm{G}=0.194, \mathrm{~T}$ $=0.255$. Ingroup cyt $b$ sequences collapsed into 21 unique haplotypes and 16S into 15 unique haplotypes. For the $16 S$-cytb data combined (32 individuals; 20 haplotypes and two outgroup taxa; $1248 \mathrm{bp}$ ), 227 included characters were parsimony informative.

\section{Phylogenetic analyses}

We found no conflicting phylogenetic signal between the cyt $b$ and 16S data (partition homogeneity test, $P=1.0$ ), justifying the use of the combined data partition in maximum parsimony (MP) analyses. Both MP and Bayesian analyses of the 16S-cytb data produced well-supported trees identical in all major topological details and with three major clades: an Upland Clade (Figure 1 localities Hola Vida, Santa Clara, EBJS, Llanganates, Cando, and Chonta Yacu), a Lowland Clade (Yasuní, Puca Chicta, EBJS, Serena, Auca 14, La Selva, and Cuyabeno); and a Southeastern clade (Kapawi and Auca 14) (Figure 2). The topology of the 16S-cytb trees is congruent with trees resulting from separate analyses of the full $16 \mathrm{~S}$ and cyt $b$ data (results not shown).

\section{Population genetics}

Corrected p-distances between E. ockendeni cyt $b$ haplotypes were high, ranging up to $20 \%$ between some haplotypes (Additional file 2). Mean net divergence \pm standard error [30] between the Southeastern Clade and the Upland Clade was $15.45 \% \pm 1.83$, between the Southeastern Clade and the Lowland Clade was $15.26 \% \pm 1.90$, and between Upland and Lowland Clades was $12.01 \% \pm 1.72$. Average sequence divergence was low within the Upland and Lowland clades, at 1.35 and $1.77 \%$ respectively, while the Southeastern Clade, which has fewer haplotypes and more geographically distant sampling, showed more intraclade diversity at $5.34 \%$.

For the cyt $b$ data, the identity of haplotypes varied among localities but seven of the 13 sites had only a single haplotype (Table 1). Nucleotide diversities within localities range from 0 to $0.105 \pm 0.079$. However, high nucleotide diversity within localities EBJS (5) and Auca 14 (7) is an artefact of finding sympatric but genetically distinct clades at those localities. When calculations of locality nucleotide diversity are separated by clade, the values range 


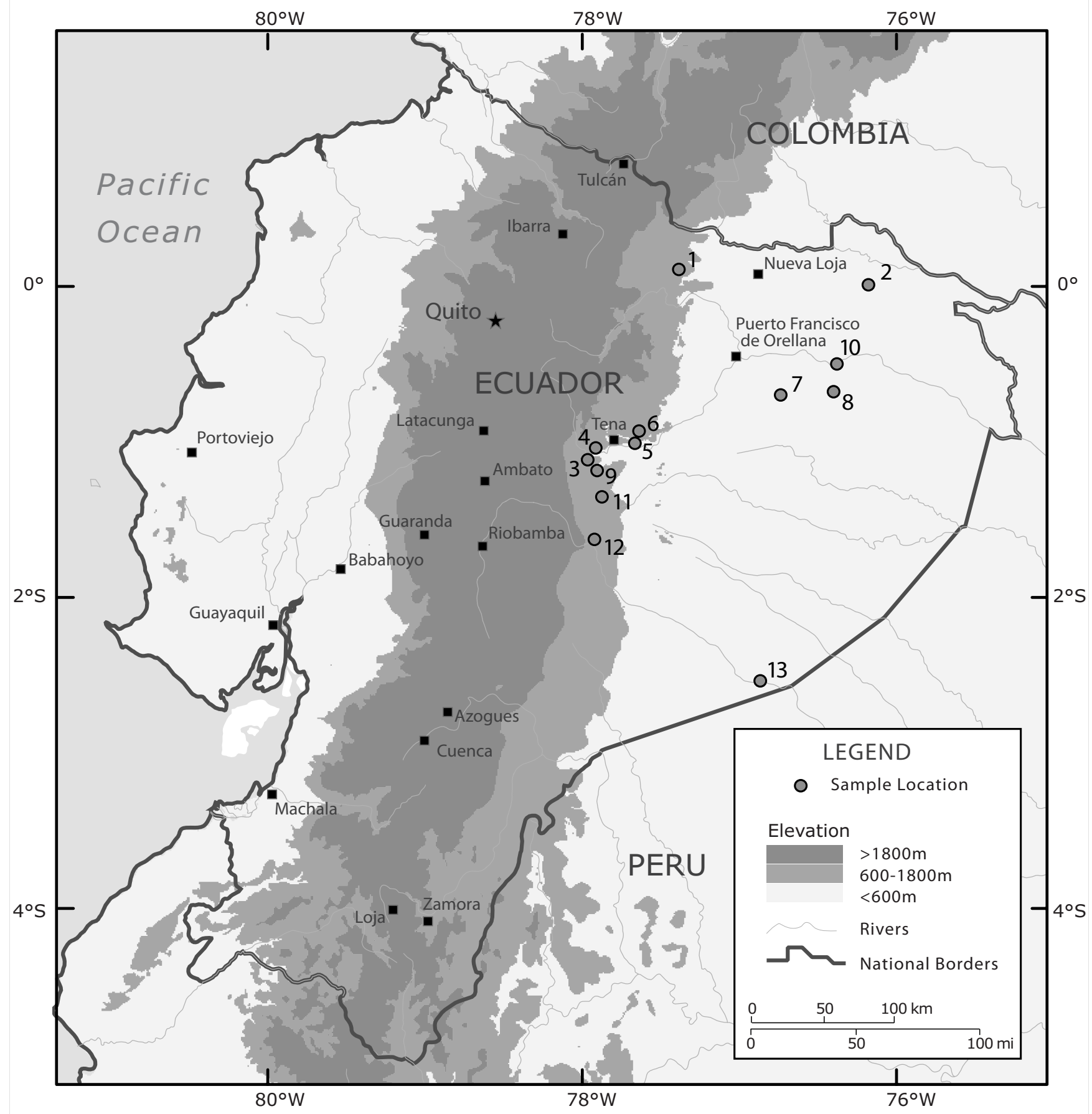

Figure I

Map of sample localities. Map of sample localities across eastern Ecuador: Chonta Yacu (I), Reserva Cuyabeno (2), Serena (3), Cando (4), Jatun Sacha Biological Station (EBJS) and surrounding area (5), Puca Chicta (6), Auca I4 Road near Dayuma (7), Parque Nacional Yasuní (8), Llanganates mountains (9), La Selva Lodge (I0), canton Santa Clara (I I), Fundación Hola Vida (I2), Kapawi Lodge (13).

from 0 to $0.0030 \pm 0.003$ (Table 1$)$. $\mathrm{HKY}+\mathrm{G}$ was the bestfit model of nucleotide substitution for cyt $b$ as chosen by hLRT.
The ratio of nonsynonymous to synonymous mutations between all pairs of clades as calculated with a McDonaldKreitman test does not suggest that selection is responsi- 
ble for the cyt $b$ divergence among lineages (Upland versus Lowland, $P=1.0$; Upland versus Kapawi, $P=1.0$; Kapawi versus Lowland, $P=0.3$ ). Overall non-significant value of Tajima's $D(0.255 ; P>0.1)$ and within clades (Upland Clade $D=-1.707, P>0.05$, Lowland Clade $D=-$ $0.834, P>0.1$, insufficient sample size to test Southeastern Clade) also implies neutrality (Table 2 ).

A survey of five tetranucleotide microsatellite loci across individuals of the Upland and Lowland clades in the Napo River area (localities 3 - 11), including a locale where both mitochondrial clades are present, shows that microsatellite genotypes at all loci are very different between Upland and Lowland clades. This implies complete reproductive isolation. The microsatellite library was developed based on Lowland Clade frogs. Consequently, in individuals from the Upland Clade the microsatellite loci are either non-functional (not amplifying after repeated attempts) or allele sizes are non-overlapping or have very different range of sizes, with the Upland Clade always having the larger mean allele size (Table 3). Sequences of large alleles from a subset of samples from three of the five loci (Eloc-Batman\&Robin, Eloc-Laurel\&Hardy, and Eloc-Thelma\&Louise) demonstrate that very large allele sizes in Upland Clade individuals are due to an increase in the number of microsatellite repeats (unpubl. data).

\section{Estimating divergence and expansion}

We used three different methods to estimate divergence: the net divergence method to estimate species divergence time; a Bayesian MCMC method to estimate lineage divergence (time to most recent common ancestor, TMRCA); and, a coalescent MCMC approach to estimate migration and TMRCA. Of these, the net divergence method and the Bayesian MCMC method (as implemented in the program BEAST) gave similar temporal results. Divergence estimates from coalescent analyses (as implemented in the program MDIV) were typically less than half the age of the other two estimates.

By the net divergence method, time of divergence between the Upland and Lowland lineages using our slowest estimated rate of evolution $(0.6 \% / M Y R)$ was $20.02 \pm 2.87$ mya (early Miocene) while the faster rate (1.0\%/MYR) estimates the same split at $12.01 \pm 1.72$ mya (midMiocene) (Table 4). Southeastern Clade split from Upland and Lowland clades approximately $25 \pm 3$ mya (late Oligocene) at the slower substitution rate and $15 \pm 2$ mya (mid-Miocene) by the faster rate.

From BEAST, assuming a constant molecular clock and rates of 0.6 and $1.0 \%$ substitutions per million years, we estimated the TMRCA of the entire ingroup to be 24.39 mya (late Oligocene) and 14.61 mya (mid-Miocene), respectively. For the TMRCA of the Upland and Lowland clades, the constant clock TMRCA estimates 15.19 mya (mid-Miocene) or 9.11 mya (late Miocene), respectively. The uncorrelated, relaxed clock estimates were not substantially different: assuming mean substitution rates of 0.6 and $1.0 \%$, the TMRCA estimates for the entire ingroup were 27.01 and 15.10 mya, respectively, while those for the Lowland/Upland clade were 15.23 and 9.03 mya, respectively (Table 5).

Coalescent calculations (implemented in the program MDIV) of the Upland and Lowland clade divergence resulted in an average $\theta$ of $6.23 \pm 0.13$ and an average $T$ of $8.78 \pm 0.31$ (Table 6). Estimates of TMRCA are 7.74 mya assuming a substitution rate of $0.6 \% / \mathrm{MYR}$ and 4.64 mya assuming the faster substitution rate of $1.0 \% / \mathrm{MYR}$. In models of Southeastern Clade versus Upland Clade divergence, $\theta$ averaged $8.43 \pm 0.27$ and $T 7.73 \pm 0.52$, suggesting a TMRCA of 10.55 mya under the slower substitution rate and 6.33 mya, with the faster rate. Models of Southeastern versus Lowland clades identified an average $\theta$ of $9.45 \pm 0.38$ and an average $T$ of $8.98 \pm 0.69$, or 9.99 mya or 7.77 mya TMRCA, depending on substitution rate. For all clade comparisons $M$ modelled best as 0 suggesting there is no gene flow among clades. The estimated time since population divergence among all clades is less than the TMRCA. MDIV estimates of TMRCA and species divergence are non-overlapping with BEAST and the net divergence method.

\section{Estimating population expansion}

We used four different methods to try and identify and estimate the timing of population expansion. Based on mismatch analyses, the sudden expansion model of population growth cannot be rejected for the Upland or the Lowland clades, although the SSD probability was marginal for the Lowland Clade $(P=0.056)$ (Table 2). Using a mutation rate of $1.0 \% / \mathrm{MYR}$ and the peak of the mismatch distribution, $\tau$, to estimate the time of population expansion suggests an Upland Clade expansion began in the latter half of the Pleistocene (793000 YBP), a Lowland Clade expansion (if it occurred) somewhat later (154000 YBP). The model of sudden population expansion is rejected for the Southeastern Clade. Raggedness indices suggest population expansion (curves are not significantly different than smooth) in all three clades. Fu's $F$ and Tajima's $D$ are not different than would be found under a stable population size. Therefore, we have conflicting evidence from different methods but some suggestion of population expansion particularly in the Upland Clade.

\section{Discussion}

\section{Phylogenetic and phylogeographic relationships}

Divergence among the three strongly supported clades in Ecuadorean E. ockendeni is deep and well supported (Fig- 
ure 2, Additional file 2). In contrast, there is relatively low divergence within the three clades. The Southeastern Clade is basal relative to the Upland and Lowland clades. The timing of the divergences for all three lineages suggests causal events that vastly predate the Pleistocene and the latter phases of orogenesis in the northern Andes. We discuss these below.

Five independent nuclear markers corroborate that the Upland and Lowland clades are evolutionarily distinct. The microsatellite loci were either non-amplifying or composed of twice as many repeats in the Upland as Lowland Clade, even in frogs from the same geographic locality (Table 3). Such differentiation at microsatellite loci between clades even when they are sympatric and the potential for interbreeding exists provides strong indirect support that these are reproductively isolated. Unfortunately, we still know little of the mate recognition system for this complex of species.

The major E. ockendeni clades are geographically restricted and found in the east Andean uplands (approx. 400 to 1000 masl; Upland Clade), the central and northern lowlands (220 to 500 masl; Lowland Clade), and the central and southern lowlands (260 to 240 masl; Southeastern Clade). Our sampling is limited to Ecuador and therefore we cannot infer whether the clades are more broadly distributed. The headwaters of the Napo River appears to be part of a lineage contact zone: at EBJS (locality 5) both the Upland and Lowland Clade can be found; slightly upriver at Serena (3) and Cando (4), the Lowland Clade is found on the south side of the Napo River while the Upland Clade is found immediately on the opposite side of the river. Further east at Auca 14 Road (locality 7), again two lineages can be found sympatrically (Upland and Southeastern clades). At all other geographic localities sampled we found only one of the three clades. Physalaemus petersi was also found to have an upper Napo and lower Napo genetic division and a basal southeastern lineage [7]. Further, an upper and lower Napo basin phylogeographic break has been suggested in Bolitoglossa salamanders [31]. Therefore, evidence from other amphibians may indicate this to be a cryptic geographic break, as has been found in other upper Amazon localities [4].

In E. ockendeni, the lack of haplotypic diversity at many localities and general lack of haplotype sharing among localities suggests fine-scale restricted gene flow (Table 1), as might be expected from a small terrestrial amphibian [27]. Population structure at finer geographic scales in the upper Amazon has also suggested restricted gene flow in this species [32].

We have included E. ockendeni from Cuyabeno (locality 2) in northeastern Ecuador in the Lowland Clade; however, they do display a notable genetic divergence from the rest of the Lowland Clade ( $>6 \%$ corrected p-distance; Additional file 2) in a group that is otherwise characterized by low within-clade diversity. Further sampling from the surrounding geographic area (e.g., northern Peru and southern Colombia) and more molecular markers will either strengthen our inclusion of Cuyabeno E. ockendeni in the Lowland Clade or differentiate it as a separate clade.

\section{Time of divergence}

Our divergence estimates suggest that diversification among the "species" E. ockendeni is ancient and predates the Andes at their current height in Ecuador. Divergence between the Southeastern and Upland/Lowland lineages occurred in the late Oligocene or early Miocene and between the Upland and Lowland Clade in the early, mid, or late Miocene, depending on substitution rate.

Of the three estimates, we consider the Bayesian phylogenetic-coalescent method (Table 5) to be the most accurate because that method accommodates the greatest number of parameters, incorporates molecular evolutionary complexities such as rate heterogeneity, allows for differences in rates among lineages, and allows for tests of the molecular clock [33]. Interestingly, and in support of a longstanding method, the much less complicated net divergence method (Table 4) has yielded very similar species divergence time estimates to the Bayesian method TMRCA. We suggest that the MDIV coalescent method (Table 6) is underestimating time of divergence in this case, perhaps because there is not enough historical information to suit a population coalescent method when species are reciprocally monophyletic and deeply diverged, or because MDIV does not accommodate rate variation among sites.

Some studies have found the rate of molecular evolution in the tropics to be equivalent to temperate areas [34,35] while others have suggested a faster rate of molecular evolution in the tropics [36-38]. Obviously, the timing of the divergence among $E$. ockendeni clades will become younger given the same genetic distance if true substitution rate is faster than we have estimated.

\section{Historical population change}

Across three different tests, there is weak and somewhat conflicting suggestion of recent population expansion under models of neutral evolution (Table 2). For the Upland Clade, we cannot reject sudden expansion from mismatch distributions or raggedness though Fu's $F$ and Tajima's $D$ do not suggest population expansion. For the Lowland Clade, we can probably reject population expansion since mismatch and raggedness significance values are only barely non-significant $(P=0.056$ for mismatch, $P$ $=0.107$ for raggedness) and $F$ and $D$ do not suggest expan- 


\section{E. acuminatus}

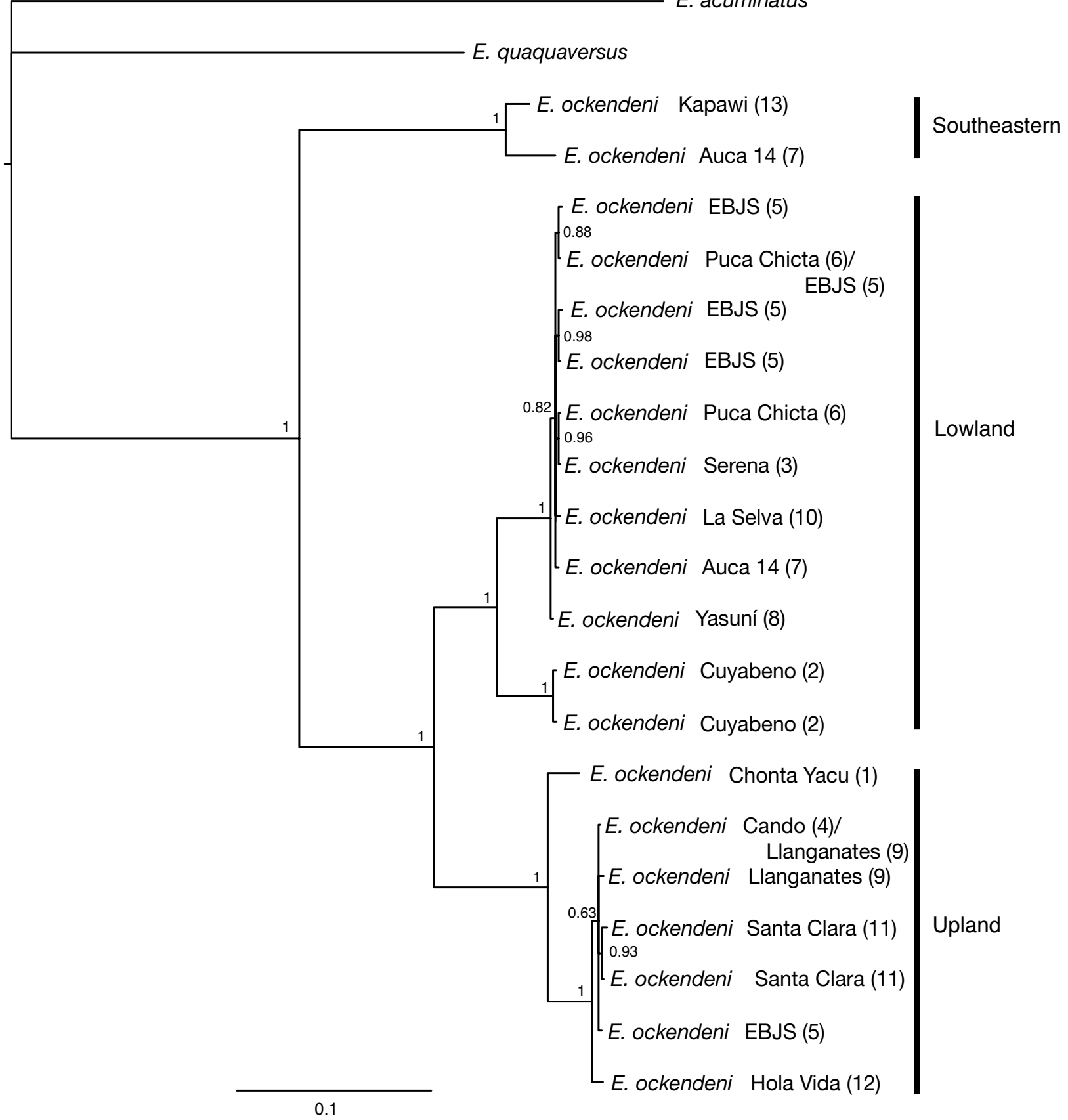

Figure 2

Phylogenetic tree of Ecuadorean E. ockendeni. Bayesian phylogenetic tree of E. ockendeni samples and two outgroup taxa. Numbers in brackets correspond to localities in Figure I. The topology and support were congruent with the MP tree. Posterior probabilities are labelled at nodes. The three major clades are noted. 
Table I: Population cyt $b$ diversities

\begin{tabular}{|c|c|c|c|c|c|c|c|}
\hline Locality & $N$ & $n$ & $h$ & $\pi$ & $s$ & Shares with & Clade \\
\hline $\begin{array}{l}\text { Chonta Yacu } \\
\text { (I) }\end{array}$ & 5 & 1 & 0 & 0 & 0 & none & Upland \\
\hline Hola Vida (I2) & 5 & $\mathrm{I}$ & 0 & 0 & 0 & none & Upland \\
\hline Cando (4) & 8 & 1 & 0 & 0 & 0 & $\begin{array}{c}\text { Llanganates, Sta } \\
\text { Clara }\end{array}$ & Upland \\
\hline Santa Clara (II) & 5 & 4 & $0.9 \pm 0.2$ & $0.0028 \pm 0.0022$ & 4 & Llanganates, Cando & Upland \\
\hline Llanganates (9) & 2 & 2 & $1.0 \pm 0.5$ & $0.0030 \pm 0.0036$ & 2 & Cando, Santa Clara & Upland \\
\hline EBJS (5) & 55 & 6 & $0.6 \pm 0.1$ & $0.0171 \pm 0.0088$ & 69 & Puca Chicta & Upland and Lowland \\
\hline Upland & 4 & 1 & 0 & 0 & 0 & none & \\
\hline Lowland & 51 & 5 & $0.5 \pm 0.7$ & $0.0013 \pm 0.0011$ & 4 & Puca Chicta & \\
\hline Puca Chicta (6) & 2 & 2 & $1.0 \pm 0.5$ & $0.0028 \pm 0.0035$ & I & EBJS, Serena & Lowland \\
\hline Serena (3) & 5 & 1 & 0 & 0 & 0 & Puca Chicta & Lowland \\
\hline Cuyabeno (2) & 2 & 2 & $1.0 \pm 0.5$ & $0.0028 \pm 0.0035$ & 2 & none & Lowland \\
\hline Yasuní (8) & 5 & 1 & 0 & 0 & 0 & none & Lowland \\
\hline La Selva (10) & 3 & I & 0 & 0 & 0 & none & Lowland \\
\hline Auca 14 (7) & 3 & 2 & $0.7 \pm 0.3$ & $0.1051 \pm 0.0790$ & 102 & none & Lowland and Southeastern \\
\hline Lowland & 2 & 1 & 0 & 0 & 0 & none & \\
\hline Southeastern & I & 1 & $1.0 \pm 0$ & 0 & 0 & none & \\
\hline Kapawi (13) & 5 & i & 0 & 0 & 0 & none & Southeastern \\
\hline
\end{tabular}

Cyt $b$ population diversity values: Locality (and corresponding number from Figure I), number of individuals sequenced ( $N$ ), number of haplotypes $(n)$, haplotype diversity $(h)$, nucleotide diversity $(\pi)$, polymorphic sites $(s)$, cyt $b$ haplotype sharing, and clade (determined from phylogenetic analyses). Where more than one clade is found at a particular locality, analyses are shown combined and separated by clade.

sion. In the Southeastern Clade, sample sizes are very small (two localities, two haplotypes), but mismatch and $F$ do not suggest population expansion while raggedness index does fit the expectation of expansion.

Our results give some support for an Upland Clade expansion in E. ockendeni approximately 800000 years ago. It is difficult to determine historical population expansion; inconclusive findings from multiple methods are not unexpected because rate heterogeneity, the scale of historical population expansion if there were any, sample size, and number of polymorphic sites are all influential fac- tors [39]. If there has been expansion in the Lowland Clade, this may have occurred 150000 years ago. In upper Amazonian clades of the terrestrial frog $P$. petersi, inconclusive results about a population expansion have also been found and, like our results here, some support for an Upper Napo clade expansion [7].

\section{Geological history and its influence on phylogeographic patterns}

The upper Amazon of Ecuador has a history of variations in climate and dramatic geology. The northern Andes are the youngest in the Andean chain: orogenesis occurred in

Table 2: Historical population expansion by clade

\begin{tabular}{|c|c|c|c|}
\hline & Upland & Lowland & Southeastern \\
\hline Mean (obs.) & 11.796 & 5.858 & 10.000 \\
\hline$\tau$ & $11.250(5.356-22.945)$ & $2.180(0.534-4.627)$ & $3.000(0.430-3.160)$ \\
\hline$\theta_{0}$ & 4.945 & 0.002 & 0.219 \\
\hline$\theta_{1}$ & 4.962 & 4.003 & 0.290 \\
\hline SSD & $0.047 P=0.458$ & $0.044 P=0.056$ & $0.155 P=0.030$ \\
\hline Raggedness Index & $0.045 P=0.640$ & $0.142 P=0.107$ & $0.667 P=0.620$ \\
\hline$t$ (MYA) & $0.793(0.378-1.618)$ & $0.154(0.038-0.326)$ & ------ \\
\hline Fu's $F$ & $2.686 P=0.880$ & $-1.547 P=0.324$ & $8.007 P=0.99$ \\
\hline Tajima's D & $-1.707 P>0.05$ & $-0.834 P>0.01$ & ----- \\
\hline
\end{tabular}

Mismatch analysis parameters by clade: mean number of observed differences; expansion parameter $\tau$ (with upper and lower bounds at $\alpha=0.05$ ); $\theta$ is the substitution rate before $(0)$ and after $(I)$ the expansion; SSD tests the validity of a stepwise expansion model based on the sum of squares deviations between the observed and expected mismatch, with probability values $(P)$. Non-significant mismatch values suggest population expansion. Raggedness Index is calculated similarly, and with probability values $(P)$. Non-significant raggedness values suggest population expansion. Time since lineage expansion $(t)$ is calculated from $\tau=2 \mu \mathrm{t}$, where $\mu=1.0 \% / M Y R$ for $709 \mathrm{bp}$. Under a model of sudden population expansion, Fu's $F$ and Tajima's $D$ are expected to be significantly negative. Some parameters are not estimated for the Southeastern Clade because of small sample sizes. 
the Neogene (Miocene through Holocene) [40], with the principle period of upheaval only in the past five million years [40-42].

Throughout the Miocene there was a radical reorganization of drainage patterns in northern South America. In the early Miocene the fluvial system drained to the northwest but by the late Miocene the effects of the rising Eastern Cordillera shifted drainage eastwards, ultimately allowing the Amazon River to reach the Atlantic [41]. Episodic marine incursions as a result of eustatic sea level changes occurred throughout the Miocene [24,41]. In the Pliocene, Pleistocene, and Holocene, fluvial deposits of many sorts and very large alluvial fans (megafans) were laid throughout the upper Amazon in the wake of Andean tectonism, volcanism, and later glaciation ([41,43-45] and references therein). These overlays and heterogeneity often leave conflicting evidence and cause geological events east of the Andes to be poorly dated $[43,46]$.

Climate also has varied over time, with great fluctuations throughout the Tertiary and Quaternary [47]. Alternating wet and dry cycles in the Pleistocene and Holocene may have caused forest contractions and expansions in some areas, though there is disagreement on the extent of this effect in the upper Amazon [21,47-49]. These forest contracts are the source of the refuge hypothesis of Amazonian diversification [20].

Clearly there are multiple possible ancient historical geological and climatic influences causing isolation and subsequent expansion in E. ockendeni, ultimately resulting in the speciation we see here. We can infer that diversification between clades of E. ockendeni predates the altitude and shape of the Andes as we know them. Instead, diversification is much older, perhaps precipitated by dramatic changes in the Miocene. For example, mountain-building caused numerous thrust faults to develop and the eastern Subandean Zone fault ([45] and references therein) approximately matches the geographic location of our
Upland/Lowland break between clades of E. ockendeni and may be historically relevant. Geological change in the Miocene has recently been suggested as influential in South American Eleutherodactylus frog diversification in general [50]. Importantly, there is no obvious contemporary barrier between the extant clades of E. ockendeni, such as a major river as would be suggested by the river barrier hypothesis [13-16]). The current lack of elevation difference in the distribution of two of the three clades suggests that elevational gradient differences are not driving the divergence (e.g., under an environmental gradient hypothesis $[51,52])$. Contemporary complex topography (as suggested by, for example $[27,53]$ ) does not seem to be relevant to patterns of deep divergence among clades, since divergence far predates existing topography, clades are not isolated by major topographic features, and the distribution of the Upland Clade extends through the headwaters of at least three major river valleys (Agua Rico, Napo, and Pastaza). Further, the genetic diversity in E. ockendeni dates from the Miocene and therefore cannot be attributed to climatic and associated vegetation changes of the past two million years, as has been suggested by proponents of the refuge theory $[11,20,54]$. However, recent population expansion in the Upland Clade may coincide with late Pleistocene climate change.

\section{Cryptic species richness in E. ockendeni}

Our findings show that the leaflitter frog species E. ockendeni is three distinct species with apparently extreme morphological conservativism. Furthermore, this area is only a portion of the species' range, which extends from southern Colombia to southern Peru [52] and Bolivia [55], so the actual species diversity and richness within "E. ockendeni" is likely much greater than that demonstrated here. When the specimens were collected and catalogued for museum deposition, there was no apparent morphological difference among specimens and there has been no published indication that there would be multiple cryptic species within this species, except for a mention that $E$. ockendeni from Cuisime (southern Ecuador) are smaller in

Table 3: Microsatellite allele sizes

\begin{tabular}{|c|c|c|c|}
\hline Locus & Lowland & Upland & Comment \\
\hline Eloc-Laurel\&Hardy & $166-262$ & --- & $\begin{array}{l}\text { Generally non-amplifying in Upland and twice the repeat } \\
\text { length vs. Lowland }\end{array}$ \\
\hline Eloc-Bert\&Ernie & $106-194$ & $202-250$ & Non-overlapping allele sizes \\
\hline Eloc-Thelma\&Louise & $|5|-247$ & $243-443$ & Non-overlapping allele sizes except in two individuals \\
\hline Eloc-Batman\&Robin & $208-282$ & $300-404$ & $\begin{array}{l}\text { Non-overlapping allele sizes (excluding four Lowland } \\
\text { individuals with possible large alleles sizes, 376-464) }\end{array}$ \\
\hline Eloc-Beauty\&Beast & $|45-22|$ & $|85-24|$ & Unequal allele size ranges \\
\hline
\end{tabular}

Microsatellite profiles (in total fragment size) by locus examined in E. ockendeni from the Napo River area (localities $3-$ II). Microsatellite allele sizes (total fragment bp) were larger in the Upland than Lowland Clade. Using E. ockendeni primers [105], one locus exclusively amplified in the Lowland Clade, suggesting it is non-functional in the Upland Clade. 
Table 4: Time of divergence among $E$. ockendeni clades based on net divergence

\begin{tabular}{|c|c|c|}
\hline Clade divergence & MYA ( \pm s.e.) at $0.6 \%$ & MYA ( \pm s.e.) at $1.0 \%$ \\
\hline Upland and Lowland & $20.02(17.15-22.88)$ & $12.01(10.29-13.73)$ \\
\hline Upland and Southeastern & $25.75(22.70-28.80)$ & $15.45(13.62-17.28)$ \\
\hline Lowland and Southeastern & $25.43(22.27-28.60)$ & $15.26(13.36-17.16)$ \\
\hline
\end{tabular}

Time of divergence estimates among monophyletic clades in millions of years (mya) calculated from net divergence among clades (upper and lower standard error bounds) assuming $0.6 \%$ and $1.0 \% /$ MYR substitution rates.

snout-vent length than those collected in other areas of Ecuador and Peru [56]. It is clear that the divergence among each of the three clades is biologically real and not an artefact of stochastic variance in mtDNA masking recent gene flow [57] because our coalescent methods model best with no gene flow among lineages (in MDIV $M=0$ ) and five nuclear microsatellite loci are significantly different between the Upland and Lowland clades. Given this new molecular information, a detailed morphological revision of Ecuadorean E. ockendeni is underway (Elmer and Cannatella, unpubl.).

Incidences of sympatric, parapatric, and allopatric cryptic species have been recently discovered in southeast Asian frogs ([58] and references within). Also, although there are exceedingly few intraspecific molecular phylogenies of neotropical amphibians, those that do exist tend to encounter new species and/or previously unanticipated species diversity $([9,59,60]$ and references within). These findings together suggest that widespread species of amphibians in the tropics have an evolutionarily history that is much more complicated than suggested by morphologies. Consequently, attempts at biological conservation according to current estimates of the number of morphological "species" will drastically underestimate the actual biodiversity in this already species-rich region.

\section{Conclusion}

We found deep phylogenetic divisions among clades in this common leaflitter frog, E. ockendeni, suggestive of distinct species. Based on microsatellite genotype profiles for distinct mitochondrial clades and modelling of historical gene flow, we suggest that there is complete reproductive isolation among these clades, even when they are sympatric. These cryptic species have an ancient divergence estimated to have originated in the Miocene. Diversification among these clades coincides approximately with periods of dramatic northern Andean orogenesis and predates the Andes at their current height. Though multiple environmental occurrences surely have been historically influential, Pleistocene climate change refuges as drivers of allopatric speciation are not relevant to extant specific diversification E. ockendeni. Our research strongly suggests that current estimates for the renowned species richness in the upper Amazon of frogs in general and Eleutherodactylus in particular may be a substantial underestimate of the actual phyletic diversity present.

\section{Methods}

\section{Field and Laboratory Methodology}

Eleutherodactylus ockendeni is a small terrestrial leaflitter frog that is relatively abundant at many upper Amazon localities [32,61,62]. Its range extends throughout the

Table 5: Time of divergence among $E$. ockendeni clades based on Bayesian coalescent estimation

\begin{tabular}{|c|c|c|c|}
\hline & clock & $\begin{array}{l}\text { at } 0.6 \% / \text { MYR } \\
\text { TMRCA (mya) }\end{array}$ & $\begin{array}{l}\text { at } 1.0 \% / M Y R \\
\text { TMRCA (mya) }\end{array}$ \\
\hline \multirow[t]{2}{*}{ Ingroup } & relaxed & $27.01(15.46-39.01)$ & I5.I (9.65-20.96) \\
\hline & constant & $24.39(18.72-30.37)$ & $14.6 \mid(11.39-18.37)$ \\
\hline \multirow[t]{2}{*}{ Upland and Lowland } & relaxed & $15.23(9.39-21.80)$ & $9.03(5.79-12.32)$ \\
\hline & constant & $15.19(11.71-19.05)$ & 9.11 (7.03-11.39) \\
\hline \multirow[t]{2}{*}{ Southeastern Clade } & relaxed & $5.08(1.79-8.62)$ & $2.70(1.19-4.81)$ \\
\hline & constant & $4.53(2.78-6.30)$ & $2.72(1.65-3.75)$ \\
\hline \multirow[t]{2}{*}{ Upland Clade } & relaxed & $5.12(2.44-8.45)$ & $2.88(1.52-4.49)$ \\
\hline & constant & $6.25(4.29-8.26)$ & $2.70(1.80-3.61)$ \\
\hline \multirow[t]{2}{*}{ Lowland Clade } & relaxed & $6.59(3.27-10.48)$ & $3.82(2.01-5.76)$ \\
\hline & constant & $4.50(3.09-6.11)$ & $3.75(2.59-4.94)$ \\
\hline
\end{tabular}

Time of divergence estimates among monophyletic clades in millions of years (mya) at $0.6 \%$ and $1.0 \% / M Y R$ substitution rates calculated from Bayesian coalescent phylogenetic estimation of time to most recent common ancestor (with $95 \%$ highest posterior density), modelled assuming a relaxed or constant molecular clock (as implemented in BEAST). 
Table 6: Estimates of time since population divergence $\left(T_{\text {pop }}\right)$ and time to most recent common ancestor $\left(T_{\text {MRCA }}\right)$, inferred using a coalescent MCMC approach to estimate migration and divergence

\begin{tabular}{|c|c|c|c|}
\hline \multicolumn{4}{|c|}{ Coalescence Divergence Time (MDIV) } \\
\hline & & at $0.6 \% / M Y R$ & at $1.0 \% / M Y R$ \\
\hline Clade comparison & & mya & mya \\
\hline \multirow[t]{2}{*}{ Upland vs. Lowland } & $T_{\text {pop }}$ & $6.45 \pm 0.11$ & $3.87 \pm 0.07$ \\
\hline & $T_{\text {MRCA }}^{\text {POP }}$ & $7.74 \pm 0.17$ & $4.64 \pm 0.10$ \\
\hline \multirow[t]{2}{*}{ Upland vs. Southeastern } & $T_{\text {pop }}$ & $7.68 \pm 0.60$ & $4.61 \pm 0.36$ \\
\hline & $T_{\text {MRCA }}^{\text {POP }}$ & $10.55 \pm 0.20$ & $6.33 \pm 0.12$ \\
\hline \multirow[t]{2}{*}{ Lowland vs. Southeastern } & $T_{\text {pop }}$ & $9.99 \pm 0.64$ & $5.99 \pm 0.38$ \\
\hline & $T_{\text {MRCA }}$ & $12.96 \pm 0.66$ & $7.77 \pm 0.40$ \\
\hline
\end{tabular}

Time estimates are based on substitution rates of $0.6 \% / M Y R$ and I.0\%/MYR.

upper Amazon of Colombia, Peru, Ecuador, Brazil [63], and Bolivia [55]. We collected from 12 localities across eastern Ecuador (Figure 1) in 2001 and 2003. Inter-locality distances ranged from 1 to $300 \mathrm{~km}$ apart (straight-line distance) and included all major river basins in Ecuador. Individuals were euthanized using MS-222 and tissue samples for genetic analyses removed and stored in pure ethanol. Specimens were fixed with $10 \%$ formalin and stored in $70 \%$ ethanol. Vouchers are deposited at the Museo de Zoología, Pontificia Universidad Católica del Ecuador (QCAZ) (Additional file 1). Samples from the Parque Nacional Yasuní locality were taken from the existing QCAZ collection.

Genomic DNA was extracted using either standard phenol-chloroform methods [64] or a Qiagen DNEasy kit according to the manufacturer's protocol. Two mtDNA fragments were amplified: $16 \mathrm{~S}$ rRNA with primers 16Sar$\mathrm{L}$ and $16 \mathrm{Sbr}-\mathrm{H}$ (ca. $560 \mathrm{bp}$; numbers 88 and 96 in [65]) and cyt $b$ with primers MVZ15L and MVZ16H (ca. 790 bp; numbers 141 and 165 in [65]). Volumes for each PCR reaction were $50 \mu \mathrm{L}$ and contained: $0.3 \mu \mathrm{M}$ of forward and reverse primer, PCR enhancing buffer $(2.5 \mathrm{mM} \mathrm{MgCl} 2,10$ $\mathrm{mM}$ Tris $\mathrm{pH} 8.4,50 \mathrm{mM} \mathrm{KCl}, 0.02 \mathrm{mg} \mathrm{BSA}, 0.01 \%$ gelatin; adapted from [66]), $0.3 \mathrm{mM}$ dNTP, 0.625 units taq DNA polymerase (Fermentas Life Sciences), and approximately 1 to 3 ng stock DNA. All reaction sets included a negative control. Cycling parameters for $16 \mathrm{~S}$ were: $94^{\circ} \mathrm{C}$ for $2 \mathrm{~min}$, 35 cycles of denaturing $94^{\circ} \mathrm{C}$ for $30 \mathrm{sec}$, annealing $60^{\circ} \mathrm{C}$ for $20 \mathrm{sec}$ and extending $72^{\circ} \mathrm{C}$ for $20 \mathrm{sec}$, a final extension at $72^{\circ} \mathrm{C}$ for $5 \mathrm{~min}$ followed by extended cooling at 10 or $4{ }^{\circ} \mathrm{C}$. Cyt $b$ parameters were: initial denaturing at $92^{\circ} \mathrm{C}$ for 3 min, 38 cycles denaturing $92^{\circ} \mathrm{C}$ for $1 \mathrm{~min}$, annealing $51^{\circ} \mathrm{C}$ for 1 min and extension $72^{\circ} \mathrm{C}$ for 1 min, a final extension of $72^{\circ} \mathrm{C}$ for $5 \mathrm{~min}$ followed by extended cooling at 4 or $10^{\circ} \mathrm{C}$. PCR product was cleaned for sequencing using a Qiaquick Gel Extraction kit according to the manufacturers' instructions for agarose electrophoresis-separated fragments or Pall AcroPrep 96 Filter Plates for PCR products that were not electrophoresed. Samples were capillary sequenced using the BigDye Terminator version
3.1 Cycle Sequencing (Applied Biosystems) chemistry on an Applied Biosystems 3100 or 3730XL Gene Analyzer.

Forty-seven individuals were sequenced for 16S: 23 in both directions and the remainder only in the forward direction. One hundred and seven individuals were sequenced for cyt $b: 41$ in both directions and the rest only in the forward direction (GenBank accession numbers: 16S EU130581 - EU130626, EU130579, EU130580; cyt $b$ EF581013-EF581063， EU130577， EU130578, EU130627-EU130680). Detailed comparison by eye of forward and reverse sequences in the overlapping regions showed no discordance in the DNA sequence used in subsequent analyses. Thirty-two individuals plus outgroup taxa had sequences for both $16 \mathrm{~S}$ and cyt $b$ (hereafter, 16Scytb). In the 16S-cytb fragment, concatenated sequences were trimmed to equal length (1248 bp), except for five sequences that remained shorter ( $\geq 1197 \mathrm{bp}$ ). In the cyt $b$ fragment, all haplotypes were the same length (709 bp) except three $(\geq 647 \mathrm{bp})$. Terminal gaps were coded as missing data.

\section{Phylogenetic Analyses}

Sequences were assembled in MACCLADE version 4.07 [67] and aligned in CLUSTAL X version 1.81 [68] using default settings. A hyper-variable loop portion of the $16 \mathrm{~S}$ alignment could not be aligned with confidence, so nine internal positions were excluded. Alignment of cyt $b$ was not problematic and included no internal gaps. The bestfit models of nucleotide substitution of cytochrome $b$, each codon position separately, and $16 \mathrm{~S}$ were estimated using MODELTEST version 3.7 [69] in PAUP* [70].

Because "intraspecific" diversity in these frogs is so high, we analyzed these data using maximum parsimony (MP) and Bayesian phylogenetic tree methods (rather than network methods [71]). Before MP analysis, we performed a partition homogeneity test [72] with 100 replicates and 10 random addition replicates per replicate in PAUP* [70] to assess whether $16 \mathrm{~S}$ and cyt $b$ have congruent phylogenetic signal. The 16S-cytb fragment MP analyses were run 
in PAUP* with outgroups Eleutherodactylus acuminatus and Eleutherodactylus quaquaversus (unistrigatus group [73]), using a heuristic search strategy with TBR branch-swapping and 1000 random addition replicates. The shortest tree was saved from each replicate. The topology of the 11 most parsimonious trees was tested with 1000 heuristic search bootstrap pseudoreplicates, with 10 random-addition replicates each, and merged into a strict $50 \%$ consensus tree. MP analyses were repeated with the full cyt $b$ and $16 S$ data sets separately. For our Bayesian phylogenetic analyses, we used a two partition (16S and cyt $b$ ) analysis in MRBAYES version 3.1.2 [74] with likelihood parameters nst $=6$, rates $=$ gamma. Two independent MCMC chains were run for 4.8 million generations with reduced temperature difference among chains $(t=0.09)$ and trees sampled every 100 generations. After assessing for apparent convergence [75], 25000 trees were discarded as burnin and a $50 \%$ majority-rule consensus tree was built.

\section{Time of divergence estimates}

We used cyt $b$ to estimate divergence times because we had more data for this fragment (individuals and haplotypes), there are more published estimates of rate of evolution available than $16 \mathrm{~S}$, and cyt $b$ is less subject to inter-study variation because of alignment-specific exclusion of hyper-variable regions typical of rDNA alignments. Divergence time among lineages or species was estimated in three ways. First, net among clade divergence ([30] p. 276) \pm standard error corrected with a TN model [76] of nucleotide substitution was calculated in MEGA3 [77]. This method subtracts the intraspecific diversity from overall divergence between two species and is unbiased when lineages are reciprocally monophyletic and ancestral population sizes is equal to the average of the two descendent species [reviewed in [78]]. Species divergence time was calculated from the net divergence estimate (net divergence $\times$ substitutions/site/MYR). The TN model is a more general case of the HKY model [79], which is implemented in MDIV (below) and was selected as an appropriate model of sequence evolution in MODELTEST.

Second, we estimated lineage divergence time, population divergence, and migration rate between major pairwise clades in MDIV [80] on CBSU Web Computing Resources. Initial runs were tested under a finite sites (HKY) model of evolution and default priors $(M=10, T=5)$ to approximate the posterior distribution of scaled migration rate $(M)$ and time since divergence $(T)$, while allowing MDIV to estimate $\theta$. Once appropriate parameter values to bound a "well-behaved" posterior distribution [80] were identified $(M=0, T=30)$, we ran the MCMC for two million generations with 500000 generations discarded as burn-in. Convergence was determined by evaluating the consistency of model values for each of the three parameters across five runs, which were then averaged to calculate mean $\theta$ and $T$ values \pm standard deviation. Time of diver- gence was calculated as (following [81]): $t_{\mathrm{div}}=(T \theta / 2 \mathrm{~L}) /(1 /$ $\mu$ ) where $T$ (or TMRCA) and $\theta$ were estimated by the height of the posterior distribution, $\mathrm{L}$ is the sequence length analyzed (709 bp of cyt $b$ ), and $\mu$ is the mutation rate (here, substitution rate). Substitution rates may be less than mutation rates because neutral mutation rates include population polymorphism that will not eventually be fixed in phylogenetic lineages (reviewed in $[82,83]$ but see [84]). Given the high levels of divergence among lineages here, we consider substitution rate more realistic than mutation rate.

As a third approach to calculating the timing of diversification, we estimated time to most recent common ancestor (TMRCA) for various clades using a Bayesian approach with the program BEAST version 1.4.1 [85]. All analyses were performed using an HKY model of nucleotide substitution with gamma distributed rate variation among sites and six rate categories. We ran four separate sets of analyses, first assuming a constant population size and a constant global molecular clock (i.e. no rate differences among lineages) of either 0.6 or $1.0 \% / \mathrm{MYR}$, and second using an uncorrelated, relaxed clock again assuming constant population size and mean clock rates of either 0.6 or $1.0 \% / M Y R$. Results from two independent runs $(10,000,000$ generations with the first $1,000,000$ discarded as burn-in and parameter values sampled every 1000 generations) for each combination of settings were combined and the effective sample size for parameter estimates and convergence checked using the program Tracer version $1.3[86]$.

The substitution rate of E. ockendeni cyt $b$ is unknown, so for all three methods we used the same two estimates of 0.6 and 1.0 substitutions/site/100 MYR. We inferred our substitution rate from two lines of evidence. First, the mtDNA gene ND2 has been found to be consistent across diverse poikilothermic vertebrate lineages (such as fish, frogs, lizards, and salamanders [87]) and to have a substitution rate similar to cyt $b$ [88]. A mean ND2 substitution rate of $0.957 \% /$ MYR has been suggested in Costa Rican Eleutherodactylus inferred from Eurasian toads [89]. Second, multiple calibrated salamander studies have found cyt $b$ substitution rates in the range of 0.6 to $0.8 \% / \mathrm{MYR}$ [90-92]. Frogs and salamanders share many characteristics that might be important in determining molecular rates of evolution (e.g., generation time, body size, ectothermy [92-94] and constancy among taxa has been shown in other mtDNA genes [87], so salamander substitution rate can be considered a reasonable approximation for frog substitution rate.

\section{Population genetics analyses - mtDNA}

We used a McDonald-Kreitman approach [95] to test for selection among clades and calculated Tajima's $D$ [96] to 
test for neutrality in DNASP version 4.10.4 [97]. Tajima's $D$ is also used for estimating population expansion.

Cyt $b$ haplotypic (gene) diversity, number of polymorphic sites, and nucleotide diversity [30] per locality were calculated in ARLEQUIN v. 2.000 [98]. Inter-haplotype TN corrected p-distances were calculated in MEGA3 [77]. Cyt $b$ mismatch distributions and raggedness index $(r)$ [99] were calculated by clade in ARLEQUIN under a model of sudden expansion using the parametric bootstrap approach ( $\alpha=0.05 ; 1000$ bootstraps) [100]. An empirical mismatch distribution that does not deviate from a unimodal distribution of pairwise differences among haplotypes and has a smooth distribution [99] suggests recent population expansion $[101,102]$. The beginning of the population expansion can be estimated from $\tau$, the crest of the mismatch distribution: $\tau=2 \mu \mathrm{t}$ [102], where $\mathrm{t}$ is the generation time (unknown, but estimated as 1 year [89]) and $\mu$ is the upper estimate divergence rate $(1.0 \% / \mathrm{MYR} \times$ number of bp). As an alternative test of population expansion, in ARLEQUIN we calculated Fu's F [103] and tested its significant with 1000 bootstrap replications. Significantly negative values of Fu's F suggest population expansion [104].

\section{Population genetics analyses - microsatellites}

Five microsatellite loci (Eloc-Bert\&Ernie, ElocBeauty\&Beast; Eloc-Thelma\&Louise; Eloc-Laurel\&Hardy and Eloc-Batman\&Robin) [105] were amplified for all individuals in the Napo River area (localities $3-11$ in Figure 1) for which we also have mtDNA sequences $(n=21$ from Upland Clade; $n=76$ from Lowland Clade). Samples were amplified and genotyped using published conditions [105]. Amplification and scoring of a subset of samples was repeated to confirm genotypes. Four samples that resulted in large microsatellites in the loci ElocThelma\&Louise and Eloc-Batman\&Robin were sequenced on an ABI 310 capillary sequencer using the microsatellite primers to determine exact composition of the microsatellite. A homozygous individual for locus Eloc-Laurel\&Hardy was amplified by PCR and cloned using pGEM-T Vector System II kit (Promega) and the inserts sequenced in an ABI 3100 sequencer using M13 primers.

\section{Authors' contributions}

KRE designed the study, collected samples, carried out the molecular studies, performed statistical analyses, and drafted the manuscript. JAD assisted with microsatellite primer design, genotyping, and microsatellite analyses, sequenced microsatellites, and interpreted results. SCL participated in the design of the study, performed statistical analyses, and helped draft the manuscript. All authors read and approved the final manuscript.

\section{Additional material}

\section{Additional file 1}

Specimen information. Museum catalogue numbers (QCAZ) for E. ockendeni and two outgroup species, GenBank accession numbers for $c y t b$ and/or 16S fragment, and locality of origin for each individual used in the study.

Click here for file

[http://www.biomedcentral.com/content/supplementary/14712148-7-247-S1.pdf]

\section{Additional file 2}

$T N$-corrected p-distance among cyt b haplotypes. TN-corrected p-distances among cyt $b$ haplotypes of $\mathrm{E}$. ockendeni, grouped by clade.

Click here for file

[http://www.biomedcentral.com/content/supplementary/14712148-7-247-S2.pdf]

\section{Acknowledgements}

We thank F. Ayala Varela, T. Sugahara, I. G. Tapia, P. Menéndez, S. Padilla, M. Bustamante, G. Vigle, and P. Grefa for assistance collecting frogs in the field. Jatun Sacha Foundation, Arajuno Jungle Lodge, P. Grefa, As. Chonta Yacu, Cabañas Lidia, M. Tapia, La Selva Jungle Lodge, Kapawi Jungle Lodge, Municipio de Arosamena Tola, M. Terry, M. Foley and D. Duncan provided lodging and support in the field. Samples were collected with permits 006 IC-FAU-DBAP/MA, 016-IC-FAU-DNBAP/MA, and 0I0-IC-FAU-DFP from Ministerio del Ambiente, Ecuador and permission of the Federación Interprovincial de Nacionalidad Achuar del Ecuador at Kapawi locality. L.A. Coloma (QCAZ) identified specimens and advised on field planning. A.J. Baker (Royal Ontario Museum) hosted KRE during the writing of this manuscript. S. Mann designed Figure I. Some of this work was carried out using the Computational Biology Service Unit resources from Cornell University that is partially funded by Microsoft Corporation. S. O'Reilly also provided computational resources. Funding for field and lab work was provided by NSERC postgraduate scholarships (KRE), a Queen's Doctoral Travel Grant (KRE), and an NSERC Discovery Grant (SCL).

\section{References}

I. Vellend M, Geber MA: Connections between species diversity and genetic diversity. Ecol Lett 2005, 8:767-78I.

2. Duellman WE: Patterns of Distribution of Amphibians: a global perspective Baltimore: The Johns Hopkins University Press; 1999.

3. Chek AA, Lougheed SC, Bogart JP, Boag PT: Perception and history: molecular phylogeny of a diverse group of neotropical frogs, the 30-chromosome Hyla (Anura: Hylidae). Mol Phylogenet Evol 200I, 18:370-385.

4. Lougheed SC, Gascon C, Jones DA, Bogart JP, Boag PT: Ridges and rivers: a test of competing hypotheses of Amazonian diversification using a dart-poison frog (Epipedobates femoralis). Proc R Soc B 1999, 266:1829-1835.

5. Symula R, Schulte R, Summers K: Molecular systematics and phylogeography of Amazonian posion frogs of the genus Dendrobates. Mol Phylogenet Evol 2003, 26:452-475.

6. Boul KE, Funk WC, Darst CR, Cannatella DC, Ryan MJ: Sexual selection drives speciation in an Amazonian frog. Proc $R$ Soc $B$ 2007, 274:399-406.

7. Funk WC, Caldwell JP, Peden CE, Padial JM, de la Riva I, Cannatella DC: Tests of biogeographic hypotheses for diversification in the Amazonian forest frog, Physalaemus petersi. Mol Phylogenet Evol 2007, 44:825-837.

8. Noonan BP, Wray KP: Neotropical diversification: the effects of a complex history on diversity within the poison frog genus Dendrobates. J Biogeogr 2006, 33:1007-1020. 
9. Lougheed SC, Austin JD, Bogart JP, Boag PT, Chek AA: Multi-character perspectives on the evolution of intraspecific differentiation in a neotropical hylid frog. BMC Evol Biol 2006, 6:23.

10. Darwin C: The Origin of Species (1928 ed.) London: Dent; 1872

II. Duellman WE: Quaternary climatic-ecological fluctuations in the lowland tropics: frogs and forests. In Biological Diversification in the Tropics Edited by: Prance GT. New York: Columbia University Press; 1982:389-402.

12. Avise JC: Phylogeography: the history and formation of species Cambridge: Harvard University Press; 2000.

13. Wallace AR: On the monkeys of the Amazon. Proc Zool Soc Lond 1852, 20:107-110.

14. Sick H: Rios e enchentes como obstäculo para a avifauna. Atas Simp Biota Amazonica (Zool) 1967, 5:495-520.

15. Gascon C, Lougheed SC, Bogart JP: Genetic and morphological differentiation in Vanzolinius discodactylus : a direct test of the riverine barrier hypothesis. Biotropica 1996, 28:376-387.

16. Gascon C, Lougheed SC, Bogart JP: Patterns of genetic population differentiation in four species of Amazonian frogs: a test of the riverine barrier hypothesis. Biotropica 1998, 30:104-119.

17. Knapp S, Mallet J: Refuting refugia? Science 2003, 300:7I-72.

18. Fjeldså J: Geographical patterns for relict and young species of birds in Africa and South America and implications for conservation priorities. Biodiv Conserv 1994, 3:207-226.

19. Haffer J: Speciation in Amazonian forest birds. Science 1969, 196: |3|-|37.

20. Simpson BB, Haffer J: Speciation patterns in the Amazonian forest biota. Ann Rev Ecol Syst 1978, 9:497-5 I8.

21. Haffer J: General aspects of the refuge theory. In Biological Diversification in the Tropics Edited by: Prance GT. New York: Columbia University Press; 1982:6-24.

22. Tuomisto $H$, Ruokolainen $\mathrm{K}$ : The role of ecological knowledge in explaining biogeography and biodiversity in Amazonia. Biodiv Conserv 1997, 6:347-357.

23. Rohde K: Latitudinal gradients in species diversity: the search for the primary cause. Oikos 1992, 65:5 I4-527.

24. Räsänen ME, Linna AM, Santos JCR, Negri FR: Late Miocene tidal deposits in the Amazonian foreland basin. Science 1995, 269:386-390.

25. Gaston KJ, Blackburn TM: The tropics as a museum of biological diversity: an analysis of the New World avifauna. Proc $R$ Soc $B$ 1996, 263:63-68.

26. Hughes C, Eastwood R: Island radiation on a continental scale: Exceptional rates of plant diversification after uplift of the Andes. Proc Natl Acad Sci USA 2006, 103:10334-10339.

27. Wake DB: Diversity of Costa Rican salamanders. In Ecology and Evolution in the Tropics: A Herpetological Perspective Edited by: Donnelly MA, Crother BI, Guyer C, Wake MH, White ME. Chicago: University of Chicago Press; 2005:65-80.

28. McKenna DD, Farrell BD: Tropical forests are both evolutionary cradles and museums of leaf beetle diversity. Proc Natl Acad Sci USA 2006, 103:10947-1095I.

29. Veith M, Kosuch J, Vences M: Climatic oscillations triggered post-Messinian speciation of Western Palearctic brown frogs. Mol Phylogenet Evol 2003, 26:3 I0-327.

30. Nei M: Molecular Evolutionary Genetics New York: Columbia University Press; 1987.

31. Elmer KR: Genetic diversity across spatial and evolutionary scales in some neotropical amphibians. In PhD thesis Queen's University, Department of Biology; 2006.

32. Elmer KR, Dávila JA, Lougheed SC: Applying new inter-individual approaches to assess fine-scale population genetic diversity in a neotropical frog, Eleutherodactylus ockendeni. Heredity in press. doi: I0.1038/sj.hdy.680I025

33. Drummond AJ, Ho SYW, Phillips MJ, Rambaut A: Relaxed phylogenetics and dating with confidence. PLoS Biology 2006, 4:e88.

34. Bromham L, Cardillo $M$ : Testing the link between latitudinal gradient in species richness and rates of molecular evolution. J Evol Biol 2003, 16:200-207.

35. Crawford AJ: Relative rates of nucleotide substitution in frogs. J Mol Evol 2003, 57:636-64l.

36. Farias IP, Ortí G, Sampaio I, Schneider H, Meyer A: Mitochondrial DNA phylogeny of the family Cichlidae: Monophyly and fast molecular evolution of the neotropical assemblage. J Mol Evol 1999, 48:703-7|।.
37. Hoegg S, Vences M, Brinkmann H, Meyer A: Phylogeny and comparative substitution rates of frogs inferred from sequences of three nuclear genes. Mol Biol Evol 2004, 2 I: I I 88- 1200.

38. Wright S, Keeling J, Gillman L: The road from Santa Rosalia: A faster tempo of evolution in tropical climates. Proc Natl Acad Sci USA 2006, 103:77/ 8-7722.

39. Aris-Brosou S, Excoffier L: The impact of population expansion and mutation rate heterogenity on DNA sequence polymorphism. Mol Biol Evol 1996, I 3:494-504.

40. Coltorti $M$, Ollier $C D$ : The significance of high planation surface in the Andes of Ecuador. In Uplift, Erosion and Stability: perspectives on long-term landscape development Edited by: Smith BJ. Whalley WB, Warke PA. London: The Geological Society of London; 1999:239-253.

4I. Hoorn C, Guerrero J, Sarmiento GA, Lorente MA: Andean tectonics as a cause for changing drainage patterns in Miocene northern South America. Geology 1995, 23:237-240.

42. van der Hammen T: Paleoecology of tropical South America. In Biological Diversification in the Tropics Edited by: Prance GT. New York: Columbia University Press; 1 982:60-66.

43. Räsänen ME, Salo JS, Jungner H, Pittman LR: Evolution of the western Amazon lowland relief: impact of Andean foreland dynamics. Terra Nova 1990, 2:320-332.

44. Christophoul F, Baby P, Soula J-C, Rosero M, Burgos J: Les ensembles fluviatiles néogènes du bassin subandin d'Équateur et implications dynamiques. CR Geoscience 2002, 334: 1029-1037.

45. Bès de Berc S, Soula JC, Baby P, Souris M, Christophoul F, Rosero J: Geomorphic evidence of active deformation and uplift in a modern continental wedge-top-foredeep transition: Example of the eastern Ecuadorian Andes. Tectonophysics 2005, 399:35I-380.

46. Pratt WT, Duque P, Ponce M: An autochthonous geological model for the eastern Andes of Ecuador. Tectonophysics 2005, 399:25I-278.

47. Räsänen ME, Salo JS, Kalliola RJ: Fluvial perturbance in the western Amazon Basin: regulation by long-term sub-Andean tectonics. Science 1987, 238:1398-|40|.

48. Weng $C$, Bush MB, Athens JS: Holocene climate change and hydrarch succession in lowland Amazonian Ecuador. Rev Palaeobot Paly 2002, I 20:73-90.

49. Bush MB, Silman MR, Urrego DH: 48,000 years of climate and forest change in a biodiversity hot spot. Science 2004, 303:827-829.

50. Heinicke MP, Duellman WD, Hedges SB: Major Caribbean and Central American frog faunas originated by ancient oceanic dispersal. Proc Natl Acad Sci USA 2007, 104:10092-10097.

5I. Graham CH, Ron SR, Santos JC, Schneider CJ, Moritz C: Integrating phylogenetics and environmental niche models to explore speciation mechanisms in dendrobatid frogs. Evolution Int J Org Evolution 2004, 58(8): 178|-1793.

52. Lynch JD, Duellman WE: The Eleutherodactylus of the Amazonian slopes of the Ecuadorian Andes (Anura: Leptodactylidae). Misc Publ Univ Kansas Mus Nat Hist 1980, 69:1-86.

53. Nevo E, Beiles A: Genetic diversity and ecological heterogeneity in amphibian evolution. Copeia 1991:565-592.

54. Haffer ]: Alternative models of vertebrate speciation in Amazonia: an overview. Biodiv Conserv 1997, 6:45 I-476.

55. Padial JM, Gonzáles L, Reichle S, Aguayo R, de la Riva I: First records of five species of the genus Eleutherodactylus Duméril and Bibron, 184I (Anura, Leptodactylidae) for Bolivia. Graellsia 2004, 60:167-174.

56. Lynch JD: A taxonomic and distributional synopsis of the Amazonian frogs of the genus Eleutherodactylus. Am Mus Nov 1980, 2696: I-24

57. Hey J, Machado CA: The study of structured populations - new hope for a difficult and divided science. Nat Rev Genet 2003, 4:535-543.

58. Stuart BL, Inger RF, Voris HK: High level of cryptic species diversity revealed by sympatric lineages of Southeast Asian forest frogs. Biol Lett 2006, 2:470-474.

59. Fouquet A, Vences M, Salducci M-D, Meyer A, Marty C, Blanc M, Gilles A: Revealing cryptic diversity using molecular phylogenetics and phylogeography in frogs of the Scinax ruber and Rhinella margaritifer species groups. Mol Phylogenet Evol 2007, 43:567-582. 
60. Ron SR, Santos JC, Cannatella DC: Phylogeny of the tungara frog genus Engystomops (= Physalaemus pustulosus species group; Anura: Leptodactylidae). Mol Phylogenet Evol 2006, 39:392-403.

61. Pearman PB: Correlates of amphibian diversity in an altered landscape in Amazonian Ecuador. Conserv Biol 1997, I I:I2I I-1225

62. Duellman WE: The biology of an equatorial herpetofauna in Amazonian Ecuador Lawrence: University of Kansas; 1978.

63. AmphibiaWeb: Information on amphibian biology and conservation [http://amphibiaweb.org]

64. Sambrook J, Fritsch EF, Maniatis T: Molecular Cloning: a Laboratory Manual 3rd edition. Cold Spring Harbour: Cold Spring Harbor Laboratory Press; 1989.

65. Goebel AM, Donnelly JM, Atz ME: PCR primers and amplification methods for I2S ribosomal DNA, the control region, cytochrome oxidase $I$, and cytochrome $b$ in bufonids and other frogs, and an overview of PCR primers which have amplified DNA in amphibians successfully. Mol Phylogenet Evol 1999, II:163-199.

66. Hagelberg E: Mitochondrial DNA from ancient bones. In Ancient DNA: Recovery and analysis of genetic material from paleontological, archaeological, museum, medical, and forensic specimens Edited by: Herrman B, Hummel S. New York: Springer-Verlag Telos; 1994.

67. Maddison DR, Maddison WP: MacClade 4: Analysis of phylogeny and character evolution. Version 4.07 Sunderland: Sinauer Associates; 2003.

68. Thompson JD, Gibson T], Plewniak F, Jeanmougin F, Higgins DG: The CLUSTAL_ $X$ windows interface: flexible strategies for multiple sequence alignment aided by quality analysis tools. Nucleic Acids Res 1997, 25:4876-4882.

69. Posada D, Crandall K: MODELTEST: testing the model of DNA substitution. Bioinformatics 1998, 14:817-818.

70. Swofford DL: PAUP*. Phylogenetic Analysis Using Parsimony (*and Other Methods). version 4 Sunderland: Sinauer Associates; 2003.

7I. Templeton AR, Crandall KA, Sing CF: A cladistic analysis of phenotypic associations with haplotypes inferred from restriction endonuclease mapping and DNA sequence data. III. Cladogram estimation. Genetics 1992, 132:619-633.

72. Farris JS, Källersjo M, Kluge AG, Bult C: Testing significance of incongruence. Cladistics 1994, 10:315-320.

73. Lynch JD, Duellman WD: Frogs of the genus Eleutherodactylus (Leptodactylidae) in western Ecuador: systematics, ecology, and biogeography. Misc Publ Nat Hist Mus Univ Kansas 1997, 23:1-236.

74. Ronquist F, Huelsenbeck JP: MRBAYES 3: Bayesian phylogenetic inference under mixed models. Bioinformatics 2003, 19:1572-1574.

75. AWTY: A system for graphical exploration of MCMC convergence in Bayesian phylogenetic inference Version 0.8 [http://ceb.csit.fsu.edu/awty]

76. Tamura K, Nei M: Estimation of the number of nucleotide substitutions in the control region of mitochondrial DNA in humans and chimpanzees. Mol Biol Evol 1993, 10:512-526.

77. Kumar S, Tamura K, Nei M: MEGA3: Integrated software for molecular evolutionary genetics. Brief Bioinform 2004, 5: I $50-163$.

78. Arbogast BS, Edwards SV, Wakeley J, Beerli P, Slowinski JB: Estimating divergence times from molecular data on phylogenetic and popuation genetic timescales. Ann Rev Ecol Syst 2002, 33:707-740.

79. Hasewaga M, Kishino H, Yano T: Dating of the human-ape splitting by a molecular clock of mitochondrial DNA. J Mol Evol 1985, 22:160-174.

80. Nielsen R, Wakeley JW: Distinguishing migration from isolation: an MCMC approach. Genetics 200I, 158:885-896.

81. Brito P: The influence of Pleistocene glacial refugia on tawny owl genetic diversity and phylogeography in western Europe. Molec Ecol 2005, 14:3077-3094

82. Nichols R: Gene trees and species trees are not the same. Trends Ecol Evol 200I, 16:358-364.

83. Ho SYW, Phillips MJ, Cooper A, Drummond AJ: Time dependency of molecular rate estimates and systematic overestimation of recent divergence times. Mol Biol Evol 2005, 22: I56I-I568.

84. Emerson BC: Alarm bells for the molecular clock? No support for Ho et al.'s model of time dependent molecular rate estimates. Syst Biol 2007, 56:337-345.

85. BEAST vI.4 [http://beast.bio.ed.ac.uk]

86. TRACER version I.3 [http://evolve.zoo.ox.ac.uk]
87. Macey JR, Strasburg JL, Brisson JA, Vredenburg VT, Jennings M, Larson $A$ : Molecular phylogenetics of western North American frogs of the Rana boylii species group. Mol Phylogenet Evol 200I, 19:|3|-|43.

88. Austin JD, Lougheed SC, Moler P, Boag PT: Phylogenetics, zoogeography, and the role of vicariance and dispersal in the evolution of the Rana catesbeiana (Anura: Ranidae) species group. Biol J Linn Soc 2003, 80:60I-624.

89. Crawford AJ: Huge populations and old species of Costa Rican and Panamanian dirt frogs inferred from mitochondrial and nuclear gene sequences. Molec Ecol 2003, I 2:2525-2540.

90. Tan A-M, Wake DB: MtDNA phylogeography of the California Newt, Taricha torosa (Caudata, Salamandridae). Mol Phylogenet Evol 1995, 4:383-394.

91. Mueller RL: Evolutionary rates, divergence dates, and the performance of mitochondrial genes in Bayesian phylogenetic analysis. Syst Biol 2006, 55:289-300.

92. Caccone A, Milinkovitch MC, Sbordoni V, Powell JR: Mitochondrial DNA rates and biogeography in European newts (genus Euproctus). Syst Biol 1997, 46:126-144.

93. Martin AP, Palumbi S: Body size, metabolic rate, generation time, and the molecular clock. Proc Natl Acad Sci USA 1993, 90:4087-409l.

94. Estabrook GF, Smith GR, Dowling TE: Body mass and temperature influece rates of mitochondrial DNA evolution in North American fish. Evolution 2007, 61:1 176-1 I87.

95. McDonald JH, Kreitman M: Adaptive protein evolution at the Adh locus in Drosophila. Nature 1991, 35 I:652-654.

96. Tajima F: Statistical method for testing the neutral mutation hypothesis by DNA polymorphism. Genetics 1989, I 23:585-595.

97. Rozas J, Sánchez-DelBarrio JC, Messeguer X, Rozas R: DnaSP, DNA polymorphism analyses by the coalescent and other methods. Bioinformatics 2003, 19:2496-2497.

98. Schneider S, Roessli D, Excoffier L: Arlequin ver. 2.000: A software for population genetics data analysis Geneva: University of Geneva, Genetics and Biometry Laboratory; 2000.

99. Harpending HC: Signature of ancient population growth in a low-resolution mitochondrial DNA mismatch distribution. Hum Biol 1994, 66:591-600.

100. Schneider S, Excoffier L: Estimation of past demographic parameters from the distribution of pairwise differences when the mutation rates vary among sites: Application to human mitochondrial DNA. Genetics 1999, I 52:1079-1089.

I0I. Slatkin M, Hudson RR: Pairwise comparisons of mitochondrial DNA sequences in stable and exponentially growing populations. Genetics 1991, I 29:555-562.

102. Rogers AR, Harpending $\mathrm{H}$ : Population growth makes waves in the distribution of pairwise genetic differences. Mol Biol Evol 1992, 9:552-569.

103. $\mathrm{Fu} \mathrm{Y}-\mathrm{X}, \mathrm{Li}$ W-H: Statistical test of neutality of mutations. Genetics 1993, 133:693-709.

104. Fu Y-X: Statistical tests of neutrality of mutations against population growth, hitchhiking and background selection. Genetics 1997, 147:915-925.

105. Elmer KR, Dávila JA, Lougheed SC: Isolation of simple and compound polymorphic tetranucleotide microsatellites for the neotropical leaflitter frog Eleutherodactylus ockendeni (Leptodactylidae). Molec Ecol Notes 2006, 6:89|-893.

Publish with BioMed Central and every scientist can read your work free of charge

"BioMed Central will be the most significant development for disseminating the results of biomedical research in our lifetime. "

Sir Paul Nurse, Cancer Research UK

Your research papers will be:

- available free of charge to the entire biomedical community

- peer reviewed and published immediately upon acceptance

- cited in PubMed and archived on PubMed Central

- yours - you keep the copyright
BioMedcentral 